\title{
O conceito de liberdade e a unidade sistemática entre razão teórica e razão prática em Kant 1
}

\author{
The concept of freedom and the systematic unity between \\ theoretical and practical reason in Kant
}

\author{
Monique Hulshof \\ mohulshof@gmail.com, \\ (Universidade Federal do ABC, São Paulo, Brasil)
}

\begin{abstract}
Resumo: Na Crítica da razão prática, 0 conceito de liberdade, apontado como "pedra angular" para se conceber a unidade sistemática entre os usos teórico e prático da razão, apresenta um problema: sua realidade objetiva quanto aos objetos práticos suprassensíveis só pode ser pensada mediante a categoria de causalidade, cuja aplicação Kant havia limitado aos objetos sensíveis na primeira Crítica. Neste artigo pretendemos explicitar como Kant soluciona este problema a partir da diferenciação entre o uso teórico da categoria de causalidade, que envolve a de terminação de objetos para conhecê-los, e a significação prática desta categoria, a partir da qual apenas concebemos a determinação da vontade a agir segundo a representação da lei moral.
\end{abstract}

Palavras-chave: Kant; liberdade; causalidade; razão prática
Abstract: In the Critique of Practical Reason, the concept of freedom, considered as the "keystone" for conceiving the systematic unity between the theoretical and practical uses of reason, raises a problem: its objective reality referred to supersensible practical objects can only be thought through the category of causality, which Kant had limited to sensible objects in the first Critique. This paper aims to explain how Kant solves this problem through the distinction between the theoretical use of the category of causality that involves determining objects in order to know them, and the practical meaning of this category, by which we only conceive the determination of the will to act according to the representation of the moral law.

Keywords: Kant; freedom; causality; practical reason

DOI: http://dx.doi.org/10.11606/issn.2318-9800.v19i2p27-37

1. As obras de Kant serão citadas com indicação do título e página da tradução para o português, seguida da indicação do volume e da página na edição da Academia (Kants gesammelte Schriften: berausgegeben von der Deutschen Akademie der Wissenschaften. Berlin: Walter de Gruyter, 1902-). 
Na parte final da Analítica da Crítica da razão prática, intitulada "Elucidação crítica", Kant se dedica a explicitar a diferença da forma sistemática desta Analítica em relação à Analítica da Crítica da razão pura. Certamente atento às objeções e descontentamentos de seus leitores que apontavam para um descompasso entre a investigação sobre o conhecimento teórico ou especulativo, realizada na primeira Crítica, e as bases lançadas para sua filosofia moral na Fundamentação da metafísica dos costumes, Kant se propõe a contrastar os dois usos distintos da razão pura em vista de sua unidade. Ele observa que essa comparação entre as Analíticas das duas Críticas se faz necessária porque a razão prática e a razão especulativa "possuem como fundamento a mesma faculdade de conhecer, na medida em que ambas são razão pura" ${ }^{\prime \prime}$.

No prefácio da Fundamentação, Kant havia indicado que esta obra de caráter introdutório ainda não consistia em uma Crítica da razão prática porque procurava apenas estabelecer o "princípio supremo da moralidade", sem considerar a relação do uso prático da razão com seu uso especulativo. À Crítica da razão pura prática caberia, portanto, a tarefa de "exibir" como se dá a unidade entre razão especulativa e razão prática a partir de "um princípio comum, porque, afinal, só pode haver uma e mesma razão, que apenas na aplicação tem de ser diversa"3. $\mathrm{Na}$ "Elucidação crítica" Kant afirma, porém, que a comparação sistemática entre as analíticas das duas primeiras Críticas só pode oferecer a expectativa de se chegar a um princípio a partir do qual se possa derivar a unidade de toda "a faculdade da razão pura (tanto da faculdade teórica como da prática)", mas não o próprio princípio ${ }^{4}$. Assim, como nos sugere Brandt, Kant não apresenta ainda nenhuma solução quanto ao problema da unidade entre razão teórica e razão prática, mas

2. KANT, I. Crítica da razão prática. KpV, AK V 89. Esta obra será citada de acordo com a paginação da academia.

3. KANT, I. Fundamentação da metafísica dos costumes. Trad. Guido de Almeida. São Paulo: Barcarolla e Discurso Editorial, 2009, p.83. AA IV 391.

4. Cf. Crítica da razão prática. AA V 91. "Para alguém que pôde se convencer pelas proposições $<$ Sätze $>$ apresentadas na Analítica, tais comparações trarão contentamento; pois elas incitam corretamente a expectativa de talvez algum dia alcançar o discernimento da unidade do todo da faculdade da razão pura (tanto da faculdade teórica quanto da prática) e de poder derivar tudo a partir de um princípio $<$ Princip $>$; o que consiste na inevitável necessidade $<$ Bedürfnis> da razão humana, que só pode encontrar inteira satisfação $<$ Zufriedenheit $>$ em uma unidade sistemática completa de seus conhecimentos". 
apenas a "intenção" de encontrar esta unidade ${ }^{5}$. De qualquer modo, Kant insiste na importância da comparação entre seus dois usos, pois é ela que torna possível se aproximar de uma conexão sistemática entre eles. Examinar suas diferenças permite compreender que o uso prático se une ao uso especulativo não como uma "escora" ou um "contraforte" acrescentado ao edifício, mas como um novo membro do sistema da razão pura.

É notável que a ideia de liberdade, em torno da qual gira a maior parte das considerações de Kant na "Elucidação crítica", cumpra um papel central na articulação entre os dois domínios do sistema razão pura. Já no prefácio Kant havia apresentado esse conceito a partir da imagem de uma "pedra angular" $<$ Schlussstein $>^{6}$. A ideia de liberdade constitui-se como o ponto de sustentação em que se conectam o uso especulativo e o prático da razão pura. Kant diz:

O conceito de liberdade, na medida em que sua realidade é provada por uma lei apodítica da razão prática, constitui agora a pedra angular de todo o edifício de um sistema da razão pura, até mesmo da razão especulativa, e todos os outros conceitos (aqueles de Deus e de imortalidade), que, enquanto meras ideias, permanecem sem apoio na razão especulativa, se anexam agora a este conceito, recebendo com ele e por ele consistência e realidade objetiva, isto é, a sua possibilidade é provada por ser efetiva a liberdade; pois essa ideia se manifesta mediante a lei moral. ${ }^{7}$

O conceito de liberdade é apresentado como o fecho do sistema da razão pura, primeiramente porque apenas este conceito tem sua realidade objetiva efetivamente assegurada pela consciência da lei moral. A liberdade, diz Kant, é "a única dentre todas as ideias da razão especulativa da qual sabemos <wissen $>$ a possibilidade a priori, sem toda-

5. BRANDT, R. Kritische Beleuchtung der Analytik der reinen praktischen Vernunft. In: HÖFFE, O. (Org.) Immanuel Kant. Kritik der praktischen Vernunft. Klassiker Auslegen Bd. 26. Berlin: Akademie Verlag, 2002, p.153-172.

6. A "pedra angular", também designada como "chave", consiste em uma pedra cortada em ângulo, colocada por último para fechar um arco e sem a qual ele não teria sustentação. Nesse sentido, é preciso notar a diferença desta metáfora com relação à da "pedra fundamental", a primeira pedra simbolicamente colocada em uma nova construção.

7. KANT, I. Crítica da razão prática, AA V, 3 . 
via discerni-la <einzusehen $>$, porque ela é a condição ${ }^{8}$ da lei moral que sabemos <wissen $>^{\prime \prime}$. Em segundo lugar, é a ideia de liberdade que sustenta a transição para um uso distinto da razão, pois somente sua efetividade permite atribuir realidade objetiva (indireta) também às outras ideias da razão especulativa, a de Deus e de imortalidade da alma.

Visto que a ideia de liberdade, entretanto, só pode ser pensada mediante a categoria de causalidade ${ }^{10}$, para estabelecê-la como ponto de sustentação entre os dois usos da razão pura, Kant tem de explicitar a legitimidade de um uso da categoria de causalidade em relação ao suprassensível no domínio prático, o qual era completamente proibido no uso teórico.

Na parte final da Analítica dos princípios, que trata "da autorização da razão pura no uso prático a uma ampliação <Erweiterung $>$ que não lhe era possível no uso especulativo", Kant expõe o problema da ampliação do uso da categoria de causalidade:

Com o princípio moral estabelecemos uma lei da causalidade que coloca o fundamento de determinação desta causalidade para além de todas as condições do mundo dos sentidos, e nós não apenas pensamos a vontade, como sendo determinável enquanto pertencente a um mundo inteligível e, portanto, o sujeito desta vontade (o homem) simplesmente enquanto pertencente a um mundo puro do entendimento, embora desconhecido nesta relação (o que, segundo a crítica da razão especulativa pura, podia acontecer), mas nós também determinamos a vontade em vista de sua causalidade, mediante uma lei que não pode ser de modo algum contada como uma lei da natureza do mundo dos sentidos; e, assim, nós ampliamos nosso

8. Sobre a liberdade como condição da lei moral, cf. Idem, AA V 4 nota: "Para que não se suponha encontrar aqui inconsequências, quando denomino agora a liberdade como condição da lei moral e depois, no tratado, afirmo que a lei moral é a condição pela qual nós podemos primeiramente nos tornar conscientes da liberdade, eu quero apenas lembrar que a liberdade é certamente a ratio essendi da lei moral, mas a lei moral é a ratio cognoscendi da liberdade. Pois, se a lei moral não fosse pensada previamente com clareza em nossa razão, nós nunca nos consideraríamos justificados a admitir algo como a liberdade (ainda que esta não se contradiga). Mas se não houvesse liberdade, então a lei moral não poderia de modo algum ser encontrada em nós".

9. Idem, $\mathrm{AA} \mathrm{V}, 4$.

10. Idem, AA V, 103. 
conhecimento para além dos limites deste mundo dos sentidos, o que é uma presunção que a Crítica da razão pura declarou por certo como nula em toda a especulação. Como é agora possível unir aqui o uso prático da razão com uso teórico desta mesma razão em vista da determinação dos limites de sua faculdade?"1

Ao expor a efetividade da razão pura prática e, com ela, uma determinação positiva da categoria de causalidade em relação ao suprassensível, a Analítica da razão prática ultrapassa a limitação das categorias ao uso empírico, isto é, sua aplicação apenas aos fenômenos e nunca às coisas em si mesmas. A vontade humana não é mais apenas pensada de maneira problemática e indeterminada, como submetida a uma causalidade livre ou numênica. Essa causalidade é agora conbecida mediante a consciência que temos da determinação da vontade segundo a lei prática incondicionada. Mais do que isso, são agora atribuídos significado e realidade objetiva ao uso da categoria de causalidade com referência aos númenos, o que era completamente negado no uso teórico.

Para compreender o problema, recordemos brevemente o que Kant entendia por realidade objetiva e significação das categorias na Analítica da primeira Crítica. Ali, Kant identifica a realidade objetiva e o significado de um conceito puro do entendimento como sua referência a um objeto determinado ${ }^{12}$. Como as categorias são meras formas do pensamento (discursivo, e não intuitivo), ainda que seja possível por meio delas pensar objetos em geral, elas só podem fornecer conhecimento de um objeto determinado se reportadas aos

11. Idem, AA V, 50.

12. Em "A pergunta pela coisa", Heidegger diferencia dois sentidos em que Kant utiliza o termo realidade (Realität). Em um sentido lato, o termo é entendido por Kant em seu sentido tradicional, afirma Heidegger, "para referir qualquer coisidade que determina também a essência da coisa como objeto". O sentido estrito é o expresso na categoria de realidade, que não deve ser entendida como existência de uma coisa, mas apenas como aquilo que "constitui" ou aquilo que "pertence" à coisa, como, por exemplo, a extensão ou a materialidade de um corpo. De acordo com Heidegger, quando se refere à realidade objetiva das categorias ou princípios do entendimento, Kant tem em mente o sentido lato e não a própria categoria da realidade (HEIDEGGER, M. Que é uma coisa? Trad. Carlos Morujão. Lisboa: Edições 70, 1987, p. 205). 
dados fornecidos pela intuição sensível, única possível para nós ${ }^{13}$. Ora, a dedução transcendental das categorias só pode demonstrar sua realidade objetiva, ou seja, sua relação aos objetos da experiência possível, na medida em que as apresenta como condição de possibilidade de todos os objetos dessa experiência. O resultado desta dedução, contudo, é a limitação de toda a aplicação das categorias aos objetos da experiência, ou seja, aos fenômenos. Há uma relação intrínseca, portanto, entre a garantia de realidade objetiva das categorias e a restrição de sua condição de aplicação.

É com essa relação intrínseca apresentada na dedução transcendental das categorias entre sua realidade objetiva e a limitação de sua aplicação aos fenômenos que Lebrun ${ }^{14}$ joga para apontar a "estrutura aporética" das afirmações de Kant sobre as coisas em si nos domínios teórico e prático da razão. A estratégia de Lebrun consiste em apresentar uma interpretação "rigorista" da limitação das categorias ao uso empírico, para logo em seguida contrastá-la com a aparente "desconsideração" dessa limitação no uso prático, em que Kant admite sua aplicação com respeito ao suprassensível.

Lebrun explicita que, na primeira Crítica, o que garante a realidade objetiva das categorias é exatamente o fato de elas não terem nenhum outro uso senão a constituição desses objetos. Por isso, além do uso empírico, elas não podem ter nenhuma aplicação e nenhum significado. Em contrapartida, Lebrun afirma que, no domínio prático, Kant desloca o acento da limitação das categorias para sua independência em relação à intuição sensível. Na segunda Crítica, Kant argumenta que o fato de ter provado a realidade objetiva dos conceitos a priori em relação aos objetos da experiência abre caminho também para uma utilização legítima desses conceitos em relação às coisas em si mesmas, na medida em que prova a independência desses conceitos em relação aos dados sensíveis. Com isso, Lebrun pretende expor um descompasso entre a fundamentação do conhecimento teórico, de um lado, e dos conceitos práticos, de outro. Ao ampliar, no domínio prático, o uso das categorias para além da restrição ao empírico, cuja

13. Cf. KANT, I. Crítica da razão pura. Trad. Fernando Costa Mattos. São Paulo: Vozes, 2012. A 156, B 195.

14. LEBRUN, G. A aporética da coisa em si. In: Sobre Kant. São Paulo: Iluminuras, 2002. 
observância é a única a garantir sua realidade objetiva, Kant estaria colocando em risco a objetividade de todo o conhecimento teórico.

O argumento de Kant para legitimar no uso prático uma "ampliação" < Erweiterung > das categorias que era impossível no uso teórico, envolve, contudo, alguns elementos não apresentados por Lebrun. Com efeito, num primeiro momento Kant retoma o resultado da dedução transcendental das categorias, afirmando que, ao demonstrar a realidade objetiva da categoria de causalidade enquanto conceito $a$ priori, demonstrou também "sua possibilidade a partir do entendimento puro", isto é, sua independência da sensibilidade quanto à sua origem. Kant reitera que a realidade objetiva das categorias só foi deduzida em vista dos objetos da experiência possível. Todavia, lembra que a independência do entendimento, enquanto pura espontaneidade, permite que este pense objetos em geral, ainda que nunca possa determiná-los a priori. Nesta medida, a categoria de causalidade pode referir-se a objetos que não são dados na experiência (coisas em si mesmas), desde que não se pretenda determinar de maneira alguma tais objetos, pois sempre faltará a condição de aplicação a esses objetos, a intuição sensível. Kant diz:

que este conceito não contenha nada de impossível, mesmo em relação a um objeto $<$ Objekt $>$, foi provado por seu lugar lhe ter sido assegurado no entendimento puro em toda aplicação aos objetos dos sentidos, e mesmo que depois, referido às coisas em si mesmas (que não podem ser objetos da experiência), não seja capaz de nenhuma determinação para as representações de um objeto determinado em função de um conhecimento teórico, ele poderia ainda assim, em função de qualquer outro uso (talvez o prático), ser capaz de uma determinação para a sua aplicação $;[\ldots]^{15}$

Nota-se aqui que ao justificar a possibilidade de referir as categorias às coisas em si mesmas, tendo em vista sua origem no entendimento puro, Kant insiste na impossibilidade de determinação da categoria de causalidade para a representação de um objeto determinado. Essa categoria fica aberta, assim, para outro tipo de determinação, desde que não envolva uma aplicação ou referência a objetos determinados.

15. KANT, I. Crítica da razão prática, AA V, 54. 
É na diferenciação do uso prático da razão em relação ao uso teórico que Kant encontra uma possibilidade de determinação, mediante o conceito de causalidade, a qual não consiste na determinação de nenhum objeto. Em seu uso prático, a razão pura não se relaciona com objetos para conhecê-los, mas com a vontade para a produção de um efeito mediante a mera representação de uma lei. Não há, portanto, uma tentativa de aplicação da categoria de causalidade a um objeto suprassensível. Muito pelo contrário. A vontade é determinada pela mera representação de uma lei prática incondicionada ou, o que é o mesmo, pela representação de um mundo inteligível, a produzir efeitos no mundo sensível ${ }^{16}$. Como nos esclarece Rousset, não se trata mais da correspondência do nosso conhecimento com o "real" dado pela intuição sensível, mas da "produção do real" segundo uma determinação incondicionada da vontade ${ }^{17}$. Nesses termos constitui-se uma nova concepção de realidade objetiva e de significação prática da categoria de causalidade, que não é mais identificada à referência a objetos determinados. Kant escreve:

A realidade objetiva de uma vontade pura ou, o que é o mesmo, de uma razão prática pura é dada a priori na lei moral, por assim dizer, por um fato $\langle$ Factum $>$; pois podemos designar assim uma determinação da vontade que é inevitável, embora não se baseie em princípios < Principien> empíricos. Mas no conceito de uma vontade já está contido o conceito de causalidade e, portanto, no conceito de uma vontade pura está contido o conceito de uma causalidade com liberdade, isto é, de uma causalidade que não é determinável segundo leis da natureza, por conseguinte, que não é capaz de nenhuma intuição empírica como prova de sua realidade, mas que ainda assim justifica perfeitamente sua realidade objetiva na lei moral prática

16. Isso fica claro na seguinte passagem: "a razão prática não tem a ver com os objetos, para os conbecer, mas com sua própria faculdade de torna-los efetivos (de acordo com o conhecimento destes), isto é, com uma vontade, que é uma causalidade, na medida em que a razão contém o fundamento de determinação desta causalidade, e, por conseguinte, [...] ela, enquanto razão prática, precisa fornecer não um objeto da intuição, mas (porque o conceito da causalidade sempre contém a referência a uma lei que determina a existência $<$ Existenz $>$ do diverso na relação com um outro), apenas uma lei desta causalidade" (Idem, AA V, 89).

17. ROUSSET, B. La Doctrine Kantienne de l'objectivité. L'autonomie comme devoir et devenir. Paris: Vrin, 1967, p. 491. 
pura a priori, certamente (como se pode facilmente discernir) não em função do uso teórico, mas meramente do uso prático da razão. [...] eu não pretendo agora com isso conbecer teoricamente a constituição de um ser na medida em que ele tem uma vontade pura ${ }_{i}$ é suficiente para mim, com isso, apenas designá-lo como tal e, portanto, apenas ligar o conceito de causalidade com o conceito de liberdade (e com aquilo que é lhe inseparável, a lei moral enquanto fundamento de determinação da vontade). ${ }^{18}$

A realidade objetiva prática da categoria de causalidade não é estabelecida por nenhuma determinação teórica do conceito que fazemos de nós mesmos enquanto númenos, ou seja, não pressupõe nenhum conbecimento de nossa existência suprassensível. Ela é assegurada unicamente pela consciência que temos, mediante a lei moral, da efetividade da razão pura prática, isto é, de que nossa vontade se determina a agir em vista da forma legislativa de nossas máximas de ação. Dito de outro modo, como se trata da produção de uma causalidade incondicionada pela razão, não é preciso apresentar aos sentidos uma intuição correspondente ao conceito de nós mesmos como seres inteligíveis ou de nossa causalidade numênica. Basta designar nossa vontade como pertencente a um mundo inteligível, ou seja, como sendo completamente determinada pela razão prática pura, e tomá-la como modelo ou como padrão para nossas ações.

Kant apresenta, assim, uma nova maneira de atribuir significado às categorias. Certamente seu significado teórico não pode ser outro senão a referência aos objetos dados pela intuição sensível. Isso não impede, todavia, que elas tenham uma função no pensamento e na compreensão de nossas ações como sendo ou não morais. A primeira Crítica abria caminho para essa significação prática ao frisar a independência do entendimento e da razão em relação à sensibilidade, enquanto auto-atividades produtoras de conceitos e ideias. A segunda Crítica, ao apresentar a razão pura, em sua relação com a vontade, como uma atividade produtora de uma legislação completamente independente da legislação natural, fornece a significação prática deste conceito $^{19}$. Esta não visa a determinação de nossa existência numênica,

18. KANT, I. Crítica da razão prática, AA V, 55-56.

19. Cf. Idem, AA V 56: "o conceito de uma causalidade empiricamente incondicionada é certamente teoricamente vazio (sem nenhuma intuição que lhe seja apropriada), mas ainda assim sempre possível, e se relaciona a um obje- 
mas apenas a representação de nós mesmos como seres autônomos (e nesse sentido, inteligíveis), a partir da qual temos uma arquétipo para julgar nossas ações.

$\mathrm{Na}$ medida em que se trata não mais de buscar um objeto dado sensivelmente que corresponda ao conceito, mas de produzir uma causalidade a partir de uma ideia de natureza suprassensível, a atribuição de realidade objetiva ou de significação prática à categoria de causalidade conduz Kant a expor uma nova condição para sua aplicação. No domínio prático, o problema da aplicação dessa categoria transforma-se no problema da efetivação do "modelo" ou do "arquétipo" suprassensível no sensível. De acordo com Silber, este problema pode ser formulado da seguinte maneira: "a ideia moral da razão exige uma efetivação empírica da própria ideia; mas não há nenhuma intuição sensível, empírica, que seja adequada a essa efetivação ${ }^{\prime 20}$. É mediante a possibilidade de representação da lei moral por meio de analogias que Kant apresentará a solução para este problema. A faculdade de julgar é mais uma vez chamada a mediar a relação entre o sensível e o inteligível, mas o modo de operar da faculdade de julgar na aplicação da lei moral aos casos particulares é distinto de como ocorria a aplicação das categorias aos fenômenos no uso teórico da razão. Assim, a leitura sugerida por Lebrun na "aporética da coisa em si" sobre um descompasso entre o projeto de legitimação do conhecimento teórico e o de fundamentação da moral talvez seja resultado de uma falta de atenção à faculdade que lhe era tão cara em Kant e o fim da metafísica: a apresentação de um novo modo de operar da faculdade de julgar na Crítica da razão prática permitirá um uso prático da categoria de causalidade que não entra em conflito com as limitações impostas pelo uso teórico da razão.

to indeterminado, e como, ao invés disso, na lei moral e, portanto, em uma relação prática, é dado a este conceito significado, então eu não possuo certamente nenhuma intuição que, para este conceito, determine sua realidade objetiva teórica, mas ele não deixa de ter aplicação efetiva $\langle$ wirklich $\rangle$, que se pode apresentar < darstellen $>$ in concreto nas disposições $<$ Gesinnungen $>$ ou máximas, isto é, não deixa de ter realidade prática que pode ser indicada <angegeben >; o que é suficiente para uma justificação mesmo em vista de númenos".

20. SILBER, J. R. Der schematismus der praktischen Vernunft. Kant-Studien, Berlin, v. 56,1966, p. $253-273$, p. 264. 


\section{Referências}

BRANDT, R. Kritische Beleuchtung der Analytik der reinen praktischen Vernunft. In: HÖFFE, O. (Org.) Immanuel Kant. Kritik der praktischen Vernunft. Klassiker Auslegen Bd. 26. Berlin: Akademie Verlag, 2002.

HEIDEGGER, M. Que é uma coisa? Trad. Carlos Morujão. Lisboa: Edições 70, 1987.

KANT, I. Kants gesammelte Schriften: herausgegeben von der Deutschen Akademie der Wissenschaften. 29 vols. Berlin: Walter de Gruyter, 1902-. Crítica da razão pura. Trad. Fernando Costa Mattos. São Paulo: Vozes, 2012.

Fundamentação da metafísica dos costumes. Trad. Guido de Almeida. São Paulo: Barcarolla e Discurso Editorial, 2009.

Crítica da razão prática. Trad. Monique Hulshof. São Paulo: Vozes (no prelo).

LEBRUN, G. Kant e o fim da metafísica. Trad. Carlos Alberto R. de Moura. São Paulo : Martins Fontes, 1993.

A aporética da coisa em si. In: Sobre Kant. São Paulo: Iluminuras, 2002

ROUSSET, B. La Doctrine Kantienne de l'objectivité. L'autonomie comme devoir et devenir. Paris: Vrin, 1967.

SILBER, J. R. Der schematismus der praktischen Vernunft. Kant-Studien, Berlin, v. 56, 1966, p. 253-273. 